\title{
An educational fuzzy temperature control system
}

\author{
Peshraw Salam ${ }^{1}$, Dogan Ibrahim ${ }^{2}$ \\ ${ }^{1}$ Department of Computer Science, University of Garmian kalar, Sulaymaniyah Kurdistan, Iraq \\ ${ }^{2}$ Department of Computer Information Systems, Near East University, Turkey
}

\begin{tabular}{l}
\hline \hline Article Info \\
\hline Article history: \\
Received Apr 3, 2019 \\
Revised Nov 24, 2019 \\
Accepted Des 9, 2019 \\
\hline
\end{tabular}

Keywords:

Educational control system

Fuzzy control

Microprocessor based control

temperature sensor

Temperature control

\begin{abstract}
Control engineering is one of the important engineering topics taught at many engineering based universities around the world in most undergraduate and postgraduate courses. The control engineering curriculum includes both the classical feedback based control theory and the state space theory. The modern control theory is based on the intelligent control algorithms utilizing the soft computing techniques, such as the fuzzy control theory and neural networks. Laboratory work is an important part of any control engineering course. The problem with the modern control theory laboratories is that it is essential to offer simple experiments to students so that they can easily put the complex theories they have learned in their courses into practice and see and understand the results. This paper describes the design of a low-cost fuzzy based microcontroller temperature control system using off the shelf products. The developed system should provide a low-cost fuzzy control experiment in the laboratories for students studying control engineering.
\end{abstract}

Copyright (C) 2020 Institute of Advanced Engineering and Science. All rights reserved.

\section{Corresponding Author:}

Dogan Ibrahim,

Department of Computer Information Systems,

Near East University,

Lefkosa, Mersin 10, Turkey.

Email: dogan.ibrahim@neu.edu.tr

\section{INTRODUCTION}

Temperature is one of the most important parameters in industrial process control, particularly in chemical engineering plants. Temperature control systems in general have nonlinear, time varying, and long time delay characteristics. Accurate control of the temperature has been an important issue in many years in the field of industrial temperature control. The automatic control theory is a complex mathematical field and it continues to grow both in terms of theory and applications [1]. Control theory has evolved in three basic stages [2]: First, on/off type simple control dominated the field where the controller output is either fully on if you are below the set-point, or fully off if you are at the set-point or above. This type of control was very easy and required no system modelling or complex mathematics, but it had many serious disadvantages such as oscillations around the set-point which gave rise undesirable behaviour [3]. Also on/off type control can damage actuators and pumps as they are rapidly switched on and off. Second, the PID based control [4] has dominated the control field for many years and the majority of industrial processes have currently been implemented with some form of PID control. Here, the controller output is derived from a signal which is proportional to the error signal, its integral, and its derivative. The PID algorithm has the advantage in implementing and providing precision controls, even in the presence of external disturbances [3]. Third, the artificial intelligence (AI) and decision-based control has become popular in the last decade as an alternative to conventional control. AI-based control systems have demonstrated to have learning and decisionmaking capabilities that are not possible in using conventional control theory [5]. Some of the commonly used artificial intelligence methods are: neural networks, fuzzy logic, genetic algorithms, probabilistic methods, and evolutionary computing. Artificial neural networks are being used to solve complex modelling, identification, 
and control problems in process control [6]. In the past, neural network based control has been used in many intelligent controllers. For example, in street lighting [7], boiler control [8], greenhouse temperature and humidity control [9], electric motor control [10], robotics [11], solar electricity systems [12], waste water treatment plants [13], and in many other controllers.

Another popular field of intelligent control systems is the field of Fuzzy Logic Control (FLC), which is based on fuzzy logic [14] theories. FLC uses linguistic control strategies to achieve the required control actions. FLC is currently been used in many diverse control applications, such as renewable energy systems [15], DC motor control [16], food and beverage processes [17], and many other applications. Although the PID control is still largely used because of its accuracy and ease of use, FLC has become very popular in recent years since it simulates human control strategy rather than complex mathematical theories [18].

It has been shown by many researchers that FLC delivers improved performance compared with a classical PID type controller [19]. Additionally, it has been reported that a combination of FLC and PID provides better control of highly non-linear dynamic processes [20]. Fuzzy logic allows the designer to specify the sensor inputs and actuator outputs of a plant using simple "If... Then...Else" type of linguistic rules which are much easier for a human to understand and enable fine tuning of such a control system [21].

This paper proposes the implementation of a low-cost fuzzy logic based microcontroller driven temperature control system for use in undergraduate and postgraduate control engineering laboratories. The novelty of the proposed system is that it was built using only a small number of off-the-shelf and very low-cost components which should be within the budgets of all educational institutions. In fact, the cost was low enough that it could also be afforded by most students. The paper describes both the hardware and software details of the proposed control system.

\section{RESEARCH METHOD}

The requirement of a temperature control system is to maintain the temperature of a plant at the desired set-point value. In a FLC based temperature control system the controller uses conditional statements between the input variables (e.g. the ambient temperature) and the output variable (e.g. the heater current). The control system developed in this paper is basically a simple temperature control system. A temperature sensor is placed close to an incandescent light bulb which is used to generate heat. The controller algorithm reads the requested temperature set-point value and the actual measured temperature, and attempts to keep the temperature at the requested set-point value. Figure 1 shows the block diagram of the developed temperature control system. Here, the system consists of a temperature process (e.g. a heater), a temperature sensor, an actuator (e.g. a heater driver module), and a microcontroller development board as the digital controller. The actual ambient temperature is read by the temperature sensor and is presented to the microcontroller, which also reads the set-point temperature. The error, which is the difference between the set-point value and the actual value read, is used to trigger the Fuzzy Inference process. After the defuzzification process, correct power is supplied to the heater driver module which increases or decreases the heater voltage in order to maintain the plant temperature at the desired set-point value.

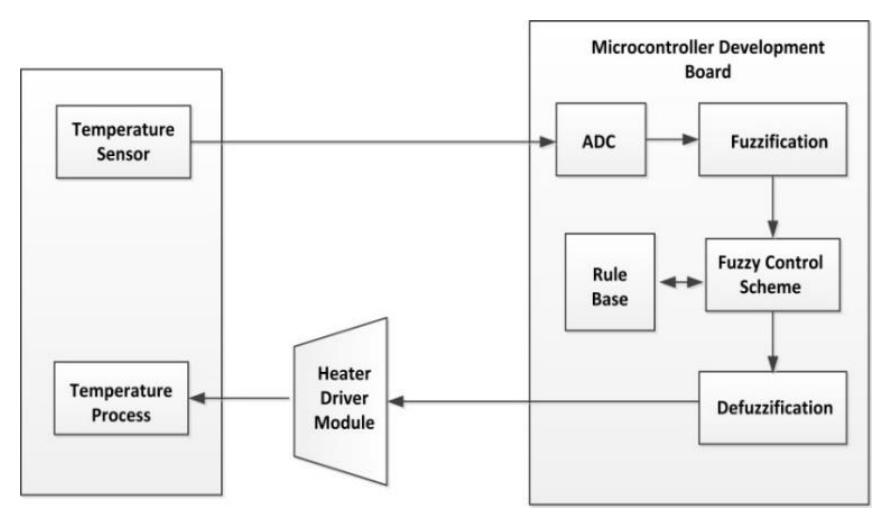

Figure 1. Block diagram of the designed fuzzy temperature control system

\subsection{The hardware}

The developed temperature control system is aimed at educational institutions with the primary consideration of keeping the overall cost as low as possible and ensuring that it is easy for the students to set up, configure and implement. Using more expensive components to produce a better learning system is 
possible, but here the goal was to design the system using easily obtained parts as well as keeping the cost low. The system has been designed around an EasyPIC microcontroller development board. A simplified hardware of the developed temperature control system is presented in Figure 2.

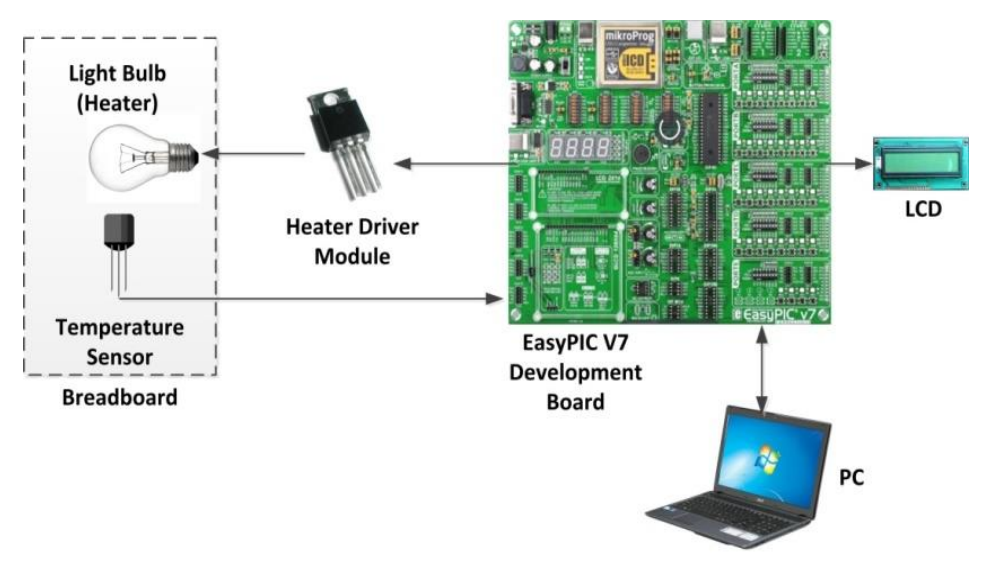

Figure 2. Hardware of the developed temperature control system

\subsubsection{The temperature sensor}

In this design a TMP36DZ type analog temperature sensor [22] chip was used. It is possible to use other low-cost analog (e.g. LM35) or digital (e.g. DS1820) temperature sensors. The reasons for the choice were two folds: Firstly, the sensor output is an analog voltage which is easy to read via an ADC channel of a microcontroller. Secondly, the sensor output voltage is linearly proportional to the measured temperature, thus no conversions are required. The sensor output voltage is given by:

$$
T=\frac{V_{s}-500}{10}
$$

where, $T$ is the measured temperature in ${ }^{\circ} \mathrm{C}$, and $V_{s}$ is the sensor output voltage in $\mathrm{mV}$. Thus, for Example, if the measured temperature is $20^{\circ} \mathrm{C}$ the sensor output voltage will be $250 \mathrm{mV}$ and so on. The ADC used has a reference voltage of $+5 \mathrm{~V}$ and is 10 -bits wide, thus having 1024 quantization levels. The voltage read from the sensor is converted into digital format and is then converted into real temperature in degrees Centigrade using the following equation:

$$
V_{S}=\frac{T_{D} \times 5000}{1024}
$$

where, $T_{D}$ is the digital equivalent of the sensor output voltage (in mV). Combining (1) and (2), the real temperature in degrees Centigrade is given by:

$$
T=\frac{T_{D} \times 500}{1024}-50
$$

\subsubsection{The temperature process (heater)}

One of the aims of the design has been to use off-the-shelf very low-cost standard components. In order to satisfy this criteria, a small $12 \mathrm{~V} 21 \mathrm{~W}$ incandescent light bulb (the ones used in the tail lamps of most cars) is used in the system as the heat generator. It was found with experimentation that the heat at the surface of such a light bulb can be in excess of $+100^{\circ} \mathrm{C}$. The light bulb was placed on a small breadboard and the temperature sensor was placed very close to the light bulb (about $1 \mathrm{~cm}$ apart), the idea here was to sense accurately the heat of the light with the sensor. Figure 3 shows the light bulb and the temperature sensor mounted on a small breadboard. 


\subsubsection{The microcontroller development board}

Any type of microcontroller development board could have been used in this design as long as it supported one ADC channel and one PWM hardware module, and also had enough input-output ports to drive an LCD. It was decided to use the EasyPIC V7 microcontroller development board [23] since it satisfied all of these requirements Figure 4. This development board was delivered with a medium performance 8-bit PIC18F45K22 microcontroller on-board, and operated with an external 8MHz crystal clock. The software was written in mikroC Pro for PIC [23] Integrated Development Environment which was based on the standard C language, with additional libraries customised for microcontroller applications. The program was compiled and the executable code was downloaded to the program memory of the target microcontroller via the on-board mikroProg programmer.

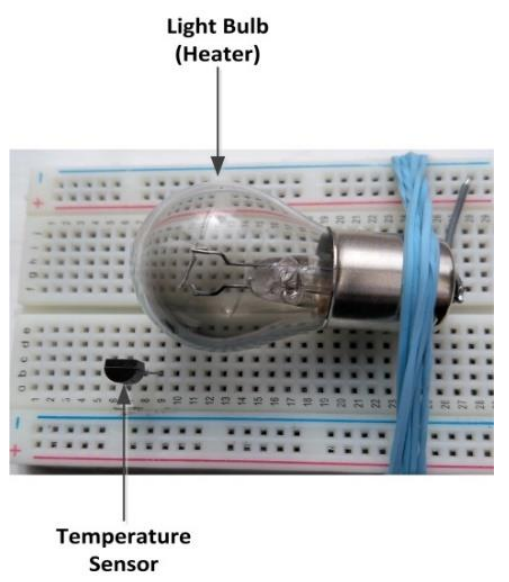

Figure 3. Light bulb (heater) and the temperature sensor chip

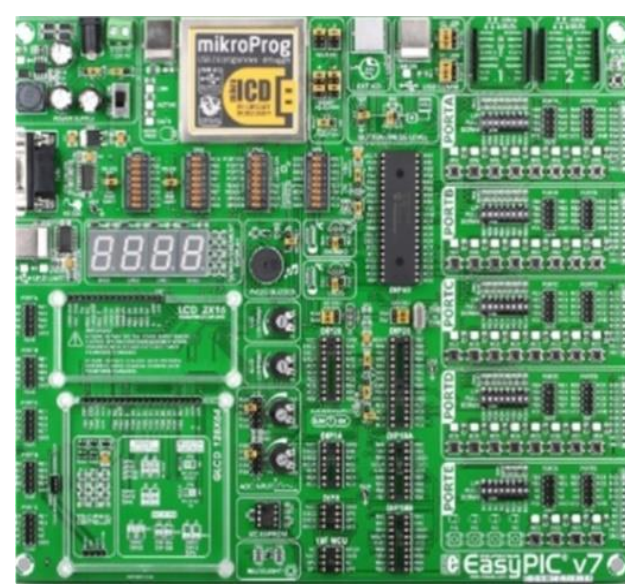

Figure 4. EasyPIC V7 development board

\subsubsection{The heater driver module}

The heater driver module was an electronic power device which controlled the voltage supplied to the heater (the light bulb in this case). Input to the heater driver was the output of the fuzzy controller and its output controlled the heater directly. In the system the heater driver was basically a Pulse Width Modulator (PWM) type signal [24] designed using a power MOSFET transistor that can switch loads with currents up to 10A. PWM is commonly used as the actuator in most power control applications, such as in motor control and in heater control. Figure 5 shows the basic waveform of a PWM signal. The duty cycle $D$, as a ratio is an important parameter of a PWM waveform and is defined as:

$$
D=\frac{T_{O N}}{T_{O N}+T_{O F F}}
$$

where $T_{O N}$ and $T_{O F F}$ are the on and off times of the waveform respectively.

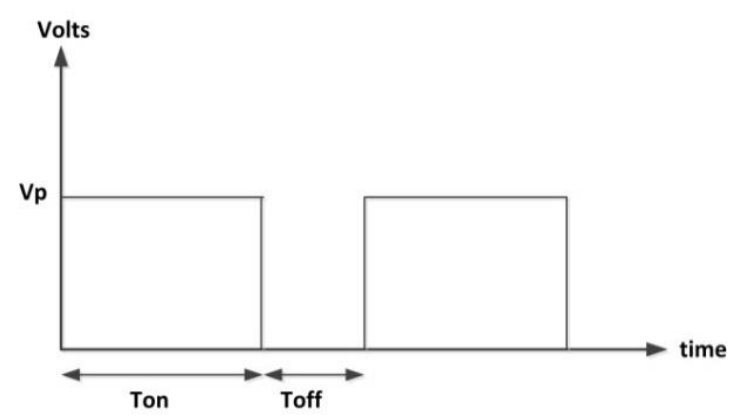

Figure 5. PWM waveform 
The duty cycle is usually written as a percentage where $0 \%$ corresponds to no power and $100 \%$ corresponds to full power [25]. Thus, by varying the duty cycle from $0 \%$ to $100 \%$ one can easily control the power delivered to the heater. Remembering that $T_{O N}+T_{O F F}$ is equal to the period $\mathrm{T}$ of the waveform, the (4) can be written as:

$$
D=\frac{T_{O N}}{T} \times 100 \%
$$

The heater responds to the RMS value of the voltage and this is also known as the effective value of the voltage. For a PWM waveform as shown in Figure 5 the RMS value is given by [26]:

$$
V_{R M S}=V_{P} \times \sqrt{D}
$$

Figure 6 shows the variation of the RMS voltage as a function of the duty cycle when the applied peak voltage is $12 \mathrm{~V}$. As it can be seen from this graph, the RMS output voltage can be controlled by controlling the duty cycle of the PWM waveform.

The important aspect was to know the transfer function of the heater driver module together with the heat generated at the surface of the incandescent bulb, and this is shown in Figure 7. This graph has been obtained by applying various duty cycles to the heater driver module and then recording the temperature measured by the temperature sensor chip after the temperature stabilized at fixed values. The graph in Figure 7 can be approximated by the following linear relationship:

$$
T=0.6 D+19
$$

where, $\mathrm{T}$ is the temperature in ${ }^{\circ} \mathrm{C}$ and $\mathrm{D}$ is the duty cycle in percentage.

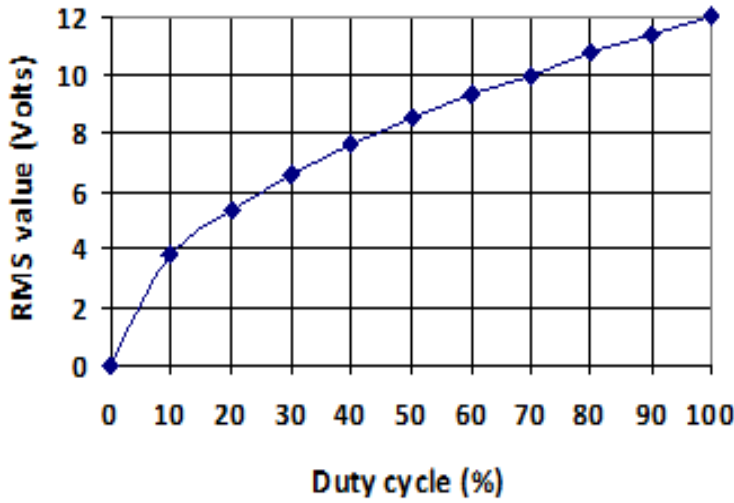

Figure 6.Variation of the RMS voltage with duty cycle

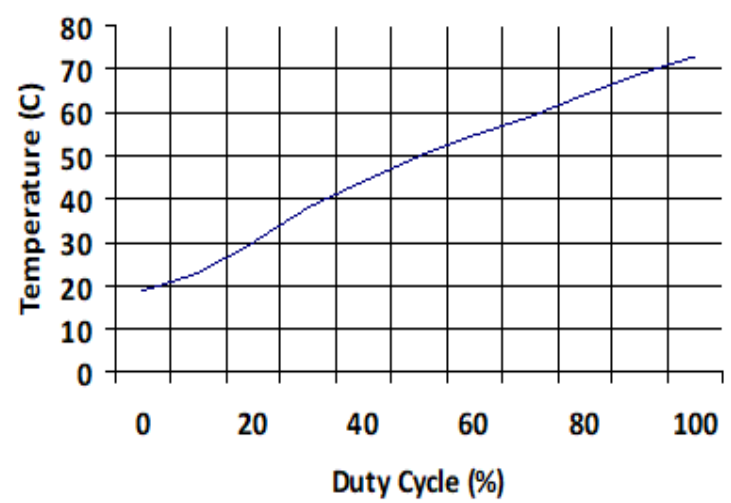

Figure 7. Temperature measured by the sensor at different duty cycles

In this system, the power MOSFET transistor IRL520N [27] was used to drive the heater from the microcontroller PWM port. The reason for choosing this transistor was because of its large current capability (10A) and large power handling (48W) capacity. The MOSFET transistor was used as a switch which turns on and off in response to the PWM signal. The PWM waveform was obtained from one of the built-in PWM hardware modules of the microcontroller [28].

\section{THE OPEN-LOOP SYSTEM}

It is interesting to know the open-loop behaviour of a system before a suitable controller can be designed for it. The open-loop transfer function of most linear systems can be obtained theoretically from knowledge of their mathematical models. If the system is non-linear or if the system model cannot be derived accurately using mathematical models, then an experimental approach can be used. One of the classical methods to derive the open-loop transfer function experimentally is to apply a step input to the system and then 
derive the transfer function experimentally by observing the system output response. Figure 8 shows the openloop step time response of the developed temperature control system. This graph was obtained by applying a step input temperature request to the heater driver module and then plotting the temperature measured by the temperature sensor chip. The response was plotted using a digital oscilloscope. As seen from this figure the open-loop system showed the typical behaviour of a first order system, having a time constant of around 300 seconds, with the transfer function shown in (8).

$$
G(s)=\frac{30 e^{-2 s}}{1+300 s}
$$

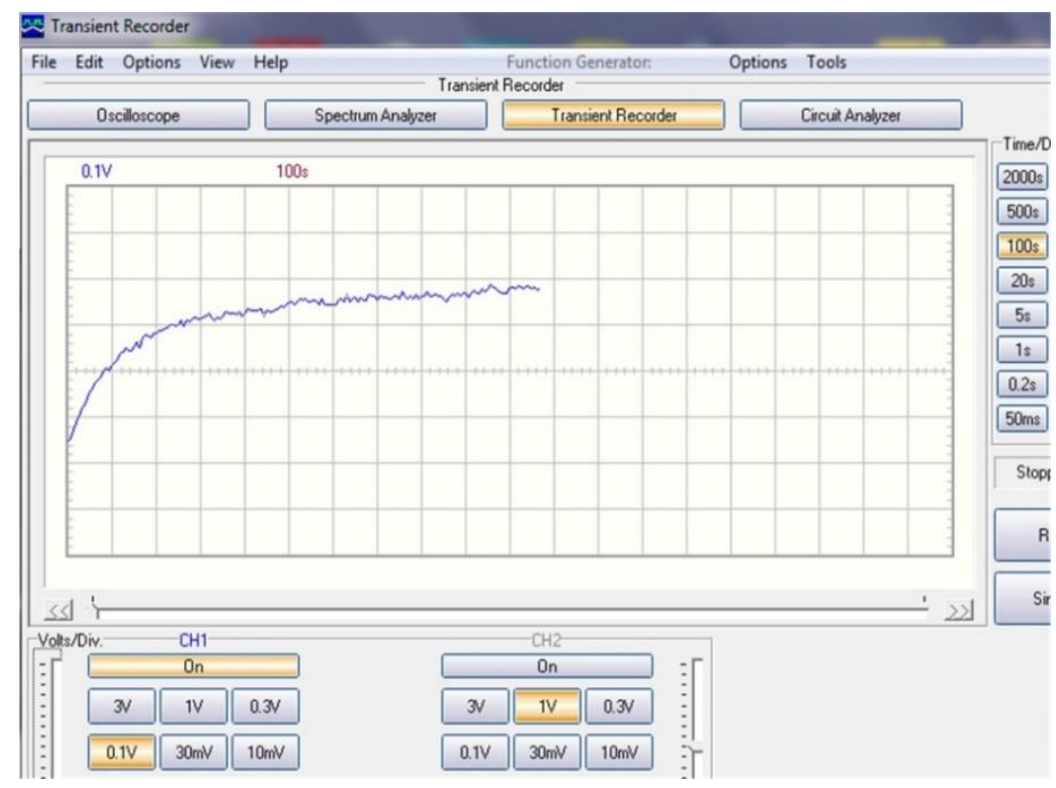

Figure 8. Open-loop step response of the system

\section{FUZZY SOFTWARE IMPLEMENTATION}

A fuzzy controller aims to control a system in a similar manner as a person. For example, in a fuzzy temperature control system, terms such as warm, hot, too hot, cold, and too cold could be used. Similarly, in a fuzzy liquid level control system, terms such as very low, low, high, and very high could be used. Conventional control methods are not suitable in many industrial process control applications due to lack of an accurate mathematical model that describes the input-output relations of the process under control [29]. In a fuzzy logic controller, the input variables are first transformed into linguistic values by the fuzzification process [30]. Then, after the implementation of the algorithm the variables are turned into crisp numerical data by the defuzzification process. Figure 9 shows the flowchart of the developed software where the process continues forever until stopped manually by the user. The operation of various parts of the software in the system is described in the remainder sections of the paper.

\subsection{Fuzzification of the inputs}

Fuzzy variables are not represented by numbers, but by linguistic terms [29, 30]. Triangular and trapezoidal membership functions are frequently used to fuzzify the inputs and it is necessary to determine the range of fuzzy variables related to the crisp inputs. Here, as shown in Table 1, the temperature range from $-10^{\circ} \mathrm{C}$ to $+50^{\circ} \mathrm{C}$ is divided into a number of groups and each group is assigned a linguistic name to represent the amount of error in the control algorithm. The following fuzzy variables are used to define the error which is the difference between the set-point and the measured temperature: $S N E G=$ small negative, NEG=negative, $\mathrm{ZERO}=$ zero, $\mathrm{SPOZ}=$ small positive, $\mathrm{POZ}=$ positive, and $\mathrm{LPOZ}=$ large positive. Figure 10 shows the graphical representation of the membership function for input error linguistic variables. Subprograms were written to receive the crisp input values and range of fuzzy variables for membership functions and then return the degree of the membership between 0 and 1 . 


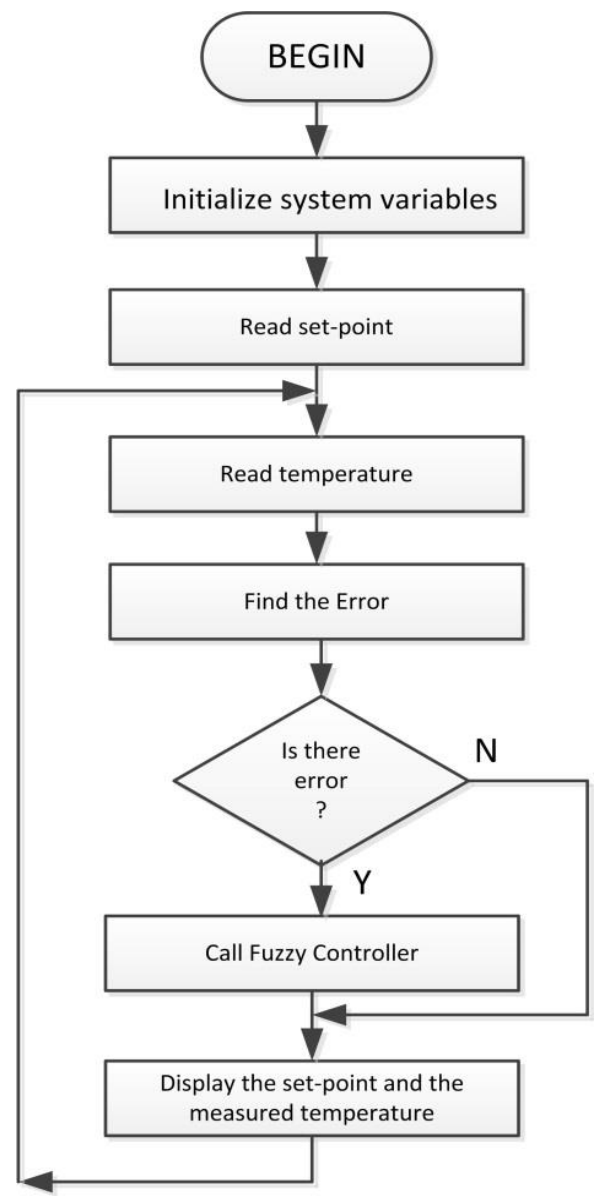

Figure 9. Flowchart of the system

Table 1. Input (error) linguistic variables

\begin{tabular}{ll}
\hline Input range (Set point-measured value) & Fuzzy variable \\
\hline-10 to -30 & NEG \\
0 to -20 & SNEG \\
-10 to +10 & ZERO \\
0 to 20 & SPOZ \\
10 to 30 & POZ \\
20 to 50 & LPOZ \\
\hline
\end{tabular}

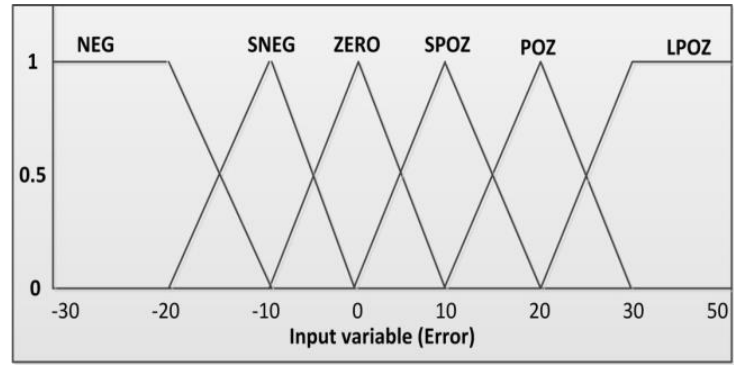

Figure 10. Graphical representation of the input error linguistic variables

\subsection{Fuzzification of the outputs}

The output linguistic variables express the values applied to the heater for the control of the temperature and these are shown in Table 2, where the duty cycle is divided into a number of groups and each group is assigned a linguistic name to represent the outputs. Figure 11 shows the graphical representation. 
Here, the duty cycle of the voltage sent to the heater is the output variable. The following fuzzy membership values were assigned for the output variable: $\mathrm{ZE}=\mathrm{zero}, \mathrm{SM}=$ small, $\mathrm{ME}=$ medium, $\mathrm{SH}=$ small high, $\mathrm{HI}=$ high, $\mathrm{VH}=$ very high.

Table 2. Output (duty cycle) linguistic variables

\begin{tabular}{ccc}
\hline Rule number & Duty cycle & Fuzzy variable \\
\hline 1 & 0 to 10 & ZE \\
2 & 10 to 40 & $\mathrm{SM}$ \\
3 & 25 to 55 & $\mathrm{ME}$ \\
4 & 40 to 70 & $\mathrm{SH}$ \\
5 & 55 to 85 & $\mathrm{HI}$ \\
6 & 70 to 100 & $\mathrm{VH}$ \\
\hline
\end{tabular}

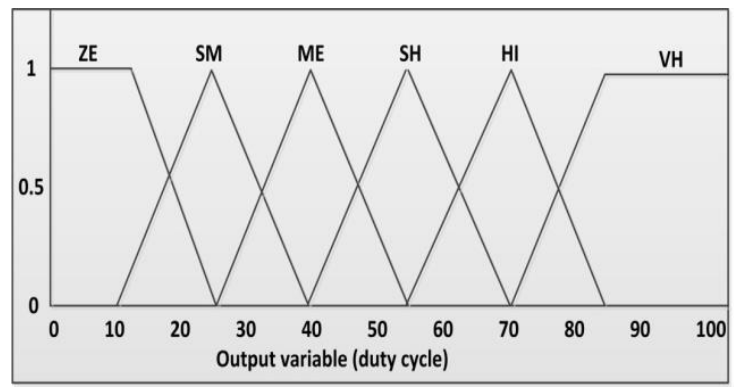

Figure 11. Graphical representation of the output linguistic variables

\subsection{Rule base}

The rule base consists of the fuzzy rules in the form of IF...ELSE blocks where the IF part represents the situation and the THEN part describes the response of the system. Table 3 shows the chosen fuzzy rules for the system.

Table 3. Rule base

\begin{tabular}{cc}
\hline IF the input error is... & THEN the duty cycle is... \\
\hline NEG & VH \\
SNEG & HI \\
ZERO & SH \\
SPOZ & ME \\
POZ & SM \\
LPOZ & ZE \\
\hline
\end{tabular}

\subsection{Defuzzification}

The process of defuzzification gives a numeric value for the duty cycle to be used to power the heater. There are many ways to carry out the defuzzification process [31, 32]. One of the popular ones, also used in this paper is the weighted average defuzzification (or the center of mass defuzzification) technique described by (9).

$$
d e f u z z=\frac{\sum_{i=1}^{6} M_{i} \times W_{i}}{\sum_{i=1}^{6} W_{i}}
$$

where, $M_{i}$ is the value of the $\mathrm{i}^{\text {th }}$ output membership function, and $W_{i}$ is the weight described by the $\mathrm{i}^{\text {th }}$ rule base. The calculated defuzzification output is used as the duty cycle to power the heater. 


\section{RESULTS AND ANALYSIS}

Figure 12 shows a typical result where the ambient temperature was $30^{\circ} \mathrm{C}$ and the set-point was at $50^{\circ} \mathrm{C}$. It is clear from this graph that the temperature settled to the desired set-point without any overshoots. Experiments with different input set-point values gave correct output responses. A small survey was conducted in order to ascertain the opinions of students who had used the developed temperature control system in one of their laboratory sessions. The aim of the survey was to find out whether the students thought that the experiment was suitable and effective as a fuzzy control learning exercise. The participants consisted of 18 third year undergraduate students studying control theory in the Electrical and Electronic Engineering course. A questionnaire was prepared consisting of 5-point Likert style type 4 questions, with 5 representing the response "Strongly Agree" and 1 representing "Strongly Disagree". Each question was phrased so that "Strongly Agree" represented a positive reaction to the developed system. Table 4 shows the participants' survey responses. It can be said that the experiment helped to learn fuzzy control, because the opinions of all the participants were scored above 4.00 for all items $(M=4.20 ; S D=0.52)$. The opinion of the participants in item 1, "I learned the practical aspects of fuzzy control through this experiment $(\mathrm{M}=4.38 ; \mathrm{SD}=0.45)$ " was given the highest positive mark by the participants. This was an interesting and encouraging result for the author. The second highest opinion was, Item 2, "I found the experiment easy to setup and implement $(\mathrm{M}=4.11 ; \mathrm{SD}=0.46)^{\prime}$.

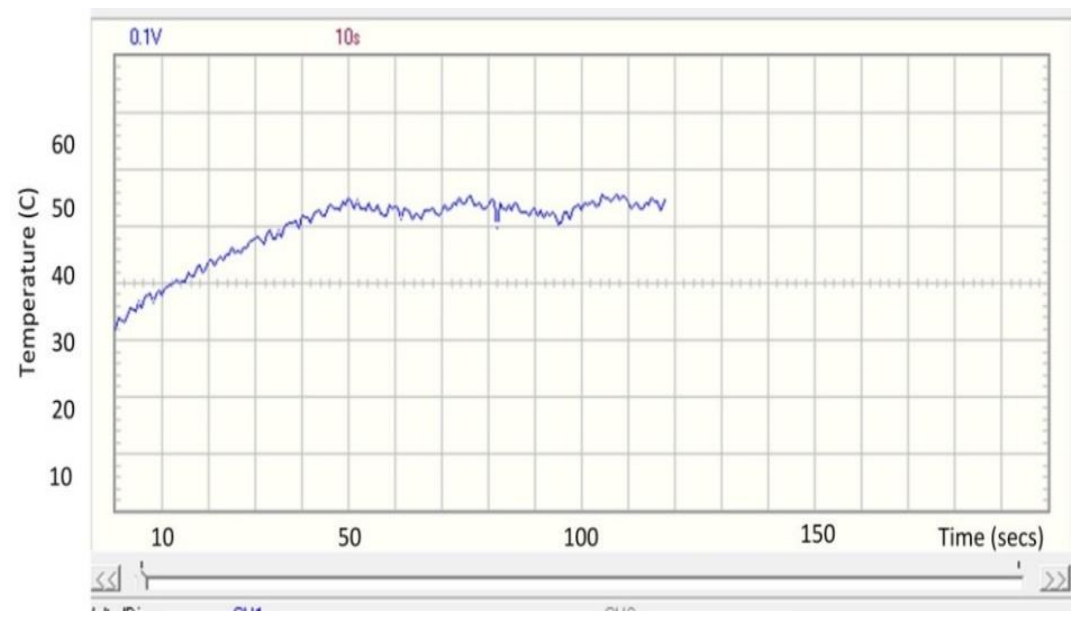

Figure 12. A typical result

Table 4. Mean and standard deviation of participants' responses

\begin{tabular}{lcc}
\hline Question & Mean & SD \\
\hline I learned the practical aspects of fuzzy control through this experiment & 4.20 & 0.52 \\
I found the experiment easy to setup and conduct & 4.38 & 0.45 \\
I did not get any help during the experiment & 4.40 & 0.48 \\
I enjoyed conducting the experiment & 4.80 & 0.40 \\
\hline
\end{tabular}

\section{CONCLUSION}

The design of a low-cost educational fuzzy temperature control system has been proposed. The most attractive feature of this system was that it was low-cost, consisted of a small lamp, a temperature sensor chip, a power transistor, and a general purpose microcontroller development board. The experimental system was easy to construct, implement, and also safe (uses low voltage), thus making it a suitable laboratory experiment for the undergraduate teaching of the modern control systems. Although the temperature control system described in this paper uses the modern fuzzy control algorithms, there is no reason why it cannot be used as a laboratory experiment for teaching the practical aspects of classical feedback control systems. For example, the system can be used in experiments to teach the practical aspects of various classical controller design algorithms such as PI, PID, and also the design of other artificial intelligence based control algorithms. The proposed fuzzy control system can be further developed by considering the following additions and/or modifications: 
The response time of the system is rather slow and it can make the students wait a long time before the system settles down to its final value. A more powerful lamp can be used as a heater to accelerate the system response. Additionally, the system response can also be improved by fitting the lamp and the temperature sensor chip in an enclosed box. Currently the temperature set-point is hard-coded inside the control algorithm. The system can be made more flexible and perhaps more user friendly by using an external potentiometer to adjust the temperature set-point.

\section{REFERENCES}

[1] R.C. Dorf, and R.H. Bishop, Modern Control Systems, 13 ${ }^{\text {th }}$ ed. London: Pearson, 2016.

[2] M. Elnour M, W.I.M. Taha, "PID and Fuzzy Logic in Temperature Control System," Int. Conf. on Computing, Electrical and Electronic Engineering (ICCEEE), Khartoum, Sudan, pp. 172-177, 2013.

[3] C.D. Johnson, Process Control Instrumentation Technology, $8^{\text {th }}$ ed. Essex: Pearson Education Ltd, 2014.

[4] J. Graf J., PID Control Fundamentals, CreateSpace Independent Publishing Platform, 2016.

[5] A. Purwar, D. Joshi, and M.S., "Dasgupta, Smart Control of Electric Lamp using Artificial Intelligence basedController," In Annual IEEE India Conference (INDICON), New Delhi, pp. 1-5, 2015

[6] F. He and C. Ma, "Modeling greenhouse air humidity by means of artificial neural network and principal component analysis," Comput and Electron Agric, vol. 71, pp. 19-23, 2010.

[7] N. Zotos et al., "Case study of a dimmable outdoor lighting system with intelligent and remote control," In Telecommunications and Multimedia (TEMU) International Conference, pp. 43-48, 2012.

[8] K. Raghupathy and R. K. Yadav, "Artificial intelligence in boiler control," 2015 International Conference on Robotics, Automation, Control and Embedded Systems (RACE), Chennai, pp. 1-6, 2015.

[9] M. Outanoute et al., "Neural network dynamic model for temperature and relative humidity control under greenhouse," In Third International Workshop on RFID and Adaptive Wireless Sensor Networks (RAWSN), Agadir, Morocco, 2015.

[10] E. Guney, M. Dursun and M. Demir, "Artificial neural network based real time speed control of a linear tubular permanent magnet direct current motor," 2017 International Conference on Control, Automation and Diagnosis (ICCAD), Hammamet, pp. 540-544, 2017.

[11] C. Sun, W. He, and J. Hong, "Neural Network Control of a Flexible Robotic Manipulator Using the Lumped SpringMass Model," IEEE Trans Syst Man Cybern Syst, vol. 47, no. 8, pp. 1863-1874, 2017.

[12] I.A. Belova, and M.V. Martinovich, "Neural network control algorithm for stand-alone solar cell electrical energy conversion system," In $16^{\text {th }}$ International Conference of Young Specialists on Micro/Nanotechnologies and Electron Devices (EDM), Erlagol, Russia, 2015.

[13] W. Zhang and J. Qiao, "Direct adaptive neural network control for wastewater treatment process," Proceeding of the 11th World Congress on Intelligent Control and Automation, Shenyang, pp. 4003-4008, 2014.

[14] E.P. Dadios, "Fuzzy logic-Controls, Concepts," Theories and Applications, Croatia: InTechOpen, 2012.

[15] L. Suganthi, S. Iniyan, and A.A. Samual, "Applications of fuzzy logic in renewable energy systems-A review," Renew Sust Energy Rev, vol. 48, pp. 585-607, 2015.

[16] S.K. Yadav, "DC Motor Position Control Using Fuzzy Proportional-Derivative Controllers With Different Defuzzification Methods," Journal of Electrical and Electronics Engineering (IOSR-JEEE), vol. 10, no. 1, pp. 37-47, 2015.

[17] S. Birle, M.A. Hussein, and T. Becker, "Fuzzy logic control and soft sensing applications in food and beverage processes," Food Control, vol. 29, no. 1, pp. 254-269, 2013.

[18] B. Srismrita B, "Realization of Fuzzy Logic Temperature Controller," Int J of Emerging Technology and Advanced Engineering, vol. 2, no. 6, 2012.

[19] M.I.H. Nour, J. Ooi, and K.Y. Chan, "Fuzzy logic control vs. conventional PID control of an inverted pendulum robot," Proceedings of 2007 ICIAS International Conference on Intelligent and Advanced Systems, pp. 209-214, 2007.

[20] E. Natsheh, and K.A. Buragga, "Comparison between Conventional and Fuzzy Logic PID Controllers for Controlling DC Motors, ” Int J of Comput Sci, vol. 7, no. 5, pp. 128-134, 2010.

[21] G.S. Nhivekar, S.S. Nirmale, and R.R. Mudholker, "Implementation of fuzzy logic control algorithm in embedded microcomputers for dedicated application," Int J of Eng Sci and Techol, vol. 3, no. 4, pp. 276-283, 2011.

[22] "Temperature sensor-TMP36," Sparkfun. [Online]. Available: https://www.sparkfun.com/products/10988. [Accessed: 2-Dec-2017].

[23] D. Ibrahim, "Non-contact Temperature Measurement in Embedded Applications," Electronics World, vol. 123(1971), pp. 14-18, 2017.

[24] S. Mahadeokar, and M. Sardeshmukh, "Energy Efficient PWM Dimmable Smart Digital LED Driver," International Conference on Energy Systems and Applications (ICESA 2015), pp. 306-311, 2015.

[25] A.K. Dewangan, et al., "PWM Based Automatic Closed Loop Speed Control of DC Motor," International Journal of Engineering Trends and Technology, vol. 3, no. 2, pp. 110-112, 2012.

[26] RMS and Average Calculator, [Online], Available: http://www.daycounter.com/Calculators/RMS-Calculator.phtml. [Accessed: 2-Dec-2017].

[27] “IRL520N data sheet," International Rectifier, [Online], Available: http://www.irf.com. [Accessed: 21-Nov-2017].

[28] PIC18F45K22 Data sheet. [Online], Available: http://www.mikroe.com [Accessed: 12-Nov-2017]. 
[29] P.S. Krishna, Process Control Engineering, Delhi: IK International Publishing House, 2013.

[30] T. Uzunovic, and I. Turkovic, "Implementation of Microcontroller Based Fuzzy Controller," $6^{\text {th }}$ IEEE International Conference on Intelligent Systems, Sofia, Bulgaria, pp. 310-315, 2012.

[31] C.P. Ugale, et al., "DC-DC Converter Using Fuzzy Logic Controller," International Research Journal of Engineering and Technology (IRJET), vol. 2, no. 4, pp. 593-596, 2015.

[32] A.R. Patil, et al., "Embedded Fuzzy Module for Battery Charger Control," Int J of Adv Res in Electr, Electron and Instr. Eng., pp. 4072-4078, 2013.

\section{BIOGRAPHIES OF AUTHORS}

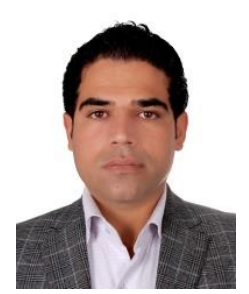

Peshraw S. Abdaladir graduated from the University of Human Development with a Bachelor's Degree in Computer Science and a Master's Degree in Computer Information Systems from Near East University in Cyprus. Peshraw S. Abdaladir currently works as a lecturer at the Department of Computer Science at the University of Garmian.

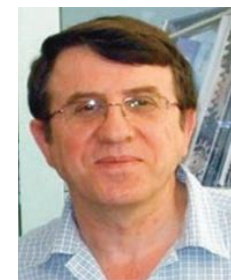

Dogan Ibrahim graduated from Salford University with first class honours in electronic engineering. He then completes MSc in automatic control engineering at the Manchester University. Prof Ibrahim then completed his PhD in electrical engineering from the City University in London. Prof Ibrahim worked in many industrial organizations before returning to the academic world. He has been the Chairman of the department of computer engineering at the Near University. Prof Ibrahim is the author of over 70 technical books published by well-known publishers. He is also the author of over 200 technical papers. Currently, Prof Ibrahim is retired and is working as a consultant. 